Goldschmidt 2021 Abstract

https://doi.org/10.7185/gold2021.5790

\section{Contrasting influence of bioturbating infauna on biogeochemical sediment dynamics and microphytobenthic primary producers}

\author{
ANAÏS RICHARD ${ }^{1}$, FRANCIS ORVAIN ${ }^{2}$, JÉRÔME \\ MORELLE $^{3}$, XAVIER DE MONTAUDOUIN ${ }^{4}$ AND OLIVIER \\ MAIRE $^{4}$ \\ ${ }^{1}$ CNRS, Univ. Bordeaux, EPOC, UMR 5805 \\ ${ }^{2}$ Univ. Normandie, Univ. Caen Normandie, FRE 2030 BOREA, \\ CNRS-7208, IRD-207, MNHN, UPMC, UCBN \\ ${ }^{3}$ University of Rennes 1 / CNRS \\ ${ }^{4}$ Univ. Bordeaux, CNRS, EPOC, EPHE, UMR 5805 \\ Presenting Author: anais.richard@u-bordeaux.fr
}

Coastal environments are among the most productive ecosystems, but also, due to global change and increasing anthropogenic pressures, among the most threatened worldwide. Regarding the benthic compartment, the degradation of habitats may profoundly alter the structure and diversity of macrofaunal communities, as well as the spatial distribution and behaviour of key species, with detrimental consequences on sediment biogeochemical processes and primary productivity.

Due to the complexity of direct and indirect factors and interactions influencing benthic ecosystem functioning, experimental measurements appear essential to better apprehend (1) the contribution of infaunal species to sedimentary processes and functions, and (2) the ecological consequences of benthic species behavioral and/or abundance variations.

To this end, this study focused on three dominant species of estuarine intertidal mudflat, the deposit-feeders Scrobicularia plana and Hediste diversicolor, and the suspension-feeder Cerastoderma edule. Particularly, we investigated the relationships between (1) respective densities, (2) sediment reworking and bioirrigation rates, (3) biogeochemical fluxes across the sediment-water interface and (4) microphytobenthic photosynthetic capacities and biomass.

Our results showed that the influence of these sedimentdwelling invertebrates on microphytobenthos (MPB) growth and physiological state does not only depend on their feeding strategy (i.e. deposit- vs. suspension-feeding) but is also indirectly mediated by their bioturbation mode and rate.

Therefore, the surface biodiffusor Scrobicularia plana, which generates a strong reworking of the sediment surface, tends to reduce MPB biomass, despite slight stimulation of nutrients fluxes. Contrariwise, the gallery-diffusor Hediste diversicolor, which strongly enhances oxygen and nutrient fluxes across the sediment-water interface through intense bioirrigation rates, stimulates MPB growth, thereby offsetting the grazing pressure. The impact of Cerastoderma edule on MPB biomass is more subtle. On one hand, it can be reduced due to horizontal displacement which generates high sediment reworking and favors MPB resuspension. On the other hand, when cockles remain immobile, MPB growth tends to be stimulated through sediment bioirrigation and stimulation of nutrients fluxes.
The relationship between density of infaunal species and MPB biomass appears not always synergistic as intraspecific competition may differentially alter feeding, sediment reworking and bioirrigation activities with contrasted effects on MPB. 